\title{
Comparison of the Behavior of Technetium and Rhenium in Low Activity Waste Glass Formulations Subjected to the Vapor Hydration Test
}

\author{
A.C. Buechele*, W.W. Lukens**, D.K. Shuh**, D.A. McKeown*, I.S. Muller*, and I.L. Pegg* \\ *Vitreous State Laboratory, The Catholic University of America, Cardinal Station, Washington, DC \\ 20064 \\ **Chemical Sciences Division, Lawrence Berkeley National Laboratory, Berkeley, CA 94720
}

Technetium (Tc) is a fission product of major concern in spent nuclear reactor fuel $\left({ }^{99} \mathrm{Tc}\right.$ half-life $2.13 \cdot 10^{5} \mathrm{y}$ ). Technetium has no stable isotopes and, thus, is essentially absent in the natural terrestrial environment. Glass is the preferred waste form for high level waste from spent fuel reprocessing. Rhenium ( $R e$ ) is often used as a non-radioactive surrogate for technetium in simulated test-glass formulations. Rhenium occurs in the periodic table one period down and in the same group as Tc, and has chemistry similar, but not identical, to Tc. This work is directed at understanding the chemical differences as they have an effect on glass aqueous corrosion tests done to assess waste form durability. Earlier work by this group [1] found different behavior for Tc and Re in glass corrosion tests, but each glass tested contained either Tc or Re, and the glass formulations were not the same.

A new series of glasses containing both elements and based on two representative low level waste glass formulations for Hanford Site envelopes " $\mathrm{A}$ " and "C" has been made with redox conditions varied during melting to produce samples with different proportions of $7+$ and $4+$ oxidation states of Tc and Re [2]. Four of the glasses (Table 1) were subjected to the Vapor Hydration Test (VHT) (ASTM C 1663-09) [3], an accelerated test exposing a glass coupon to saturated water vapor at $200^{\circ} \mathrm{C}$, usually for 24 days, but in this case for 30 days. The VHT produces a corroded layer on the glass coupon (Figs. 1-2 show layers on glasses 205 and 219); and the amount of unmodified glass remaining after the test is used as a measure of glass durability. Glasses were examined before and after the VHT using X-ray Absorption Near Edge Spectroscopy (XANES) to determine the proportions of Tc and Re present in different oxidation states in the altered layers [2]. Scanning Electron Microscopy (SEM) was used with Wavelength Dispersive Spectroscopy (WDS) to profile the elemental concentrations, especially Tc and Re, in the cross sectioned VHT specimens and to examine the structure of the corroded layer and secondary phases contained therein. Analytical conditions were employed to achieve a detection limit of $\sim 0.001 \mathrm{wt} \%$ for both $\mathrm{Tc}$ and Re.

Concentration profile behaviors of Tc and Re in the corroded layers were similar in 206 and 210, but very different in 205 and 219. Substantial reduction of $\mathrm{Tc}^{7+}$ occurred in corroded layers while $\mathrm{Re}^{7+}$ either was not or was less reduced (Figs. 3-4 show results for glasses 205 and 219; concentrations are un-normalized WDS data). These results indicate that Re is not a reliable surrogate to use for Tc in aqueous corrosion tests, and that better models for Tc behavior need to be found. Otherwise, the best alternative would be to do corrosion studies using Tc-containing glasses to obtain reliable data.

References:

[1] D.A. McKeown, A.C. Buechele, W.W. Lukens, D.K. Shuh, and I.L. Pegg, Environmental Science and Tech. 41 (2007) 431-436. 
[2] W.W. Lukens, D.A. McKeown, A.C. Buechele, I.S. Muller, D.K. Shuh and I.L. Pegg, Chem. Mater., 19 (2007) 559-566.

[3] ASTM International, West Conshohocken, PA (2009).

[4] This work supported in part by grant DE-FG02-04ER63814 to Catholic University from the U.S.

Department of Energy's Environmental Management Science Program (U.S. DOE EMSP).

TABLE 1. Analyzed glass compositions. (Entries are in wt\% and are normalized.)

\begin{tabular}{|c|c|c|c|c|c|c|c|c|c|c|c|c|c|c|c|}
\hline Glass & $\mathbf{A l}_{2} \mathbf{O}_{3}$ & $\mathbf{B}_{2} \mathbf{O}_{3}$ & $\mathrm{CaO}$ & $\mathrm{Fe}_{2} \mathrm{O}_{3}$ & $\mathrm{~K}_{2} \mathrm{O}$ & $\mathbf{L i}_{2} \mathbf{O}$ & MgO & $\mathrm{Na}_{2} \mathrm{O}$ & $\mathbf{R e}_{2} \mathbf{O}_{7}$ & $\mathrm{SiO}_{2}$ & $\mathrm{TcO}_{2}$ & $\mathrm{TiO}_{2}$ & $\mathrm{ZnO}$ & $\mathrm{ZrO}_{2}$ & Others \\
\hline 205* & 6.13 & 9.36 & 4.74 & 5.44 & 0.20 & 2.61 & 1.76 & 13.98 & 0.22 & 47.61 & 0.034 & 1.40 & 3.19 & 2.95 & 0.376 \\
\hline 206 & 5.78 & 8.89 & 2.10 & 6.91 & 3.86 & 0.16 & 2.07 & 17.92 & 0.09 & 43.93 & 0.012 & 2.08 & 3.13 & 2.80 & 0.268 \\
\hline 210 & 5.60 & 9.20 & 1.92 & 7.10 & 4.05 & 0.04 & 2.24 & 17.96 & 0.14 & 43.61 & 0.019 & 2.15 & 2.99 & 2.78 & 0.201 \\
\hline 219 & 5.79 & 8.48 & 2.25 & 7.15 & 2.80 & 0.25 & 2.39 & 17.43 & 0.04 & 44.87 & 0.004 & 2.22 & 3.15 & 2.93 & 0.246 \\
\hline
\end{tabular}

*Type C; others are type A. Liquid scintillation used to determine Tc; all other elements determined by DCP.

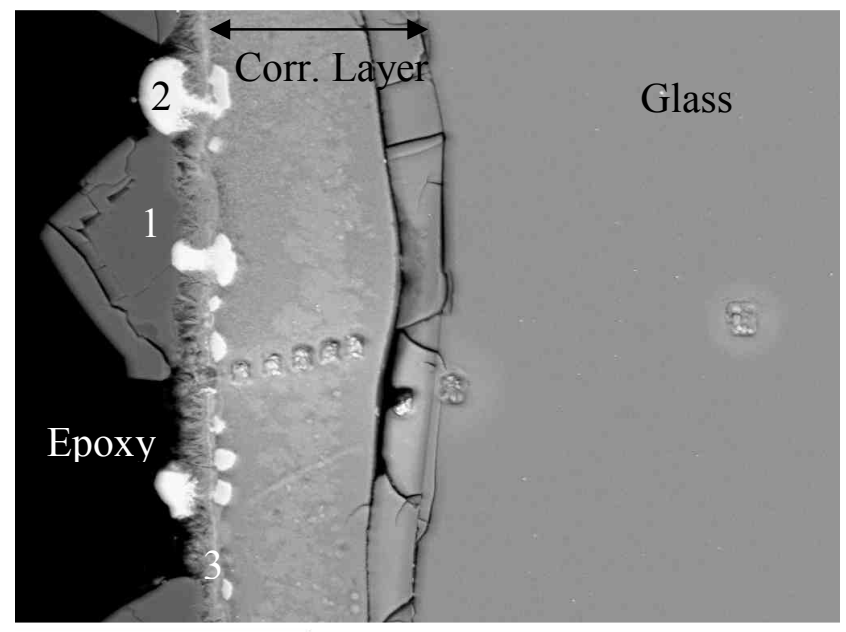

$100 \mu \mathrm{m}$

FIG. 1. Corroded layer on glass 205. Craters are WDS sampling points for composition profile. Outer surface crystals: 1 . analcime, 2. sodium zinc silicate, 3 . sodium calcium silicate.

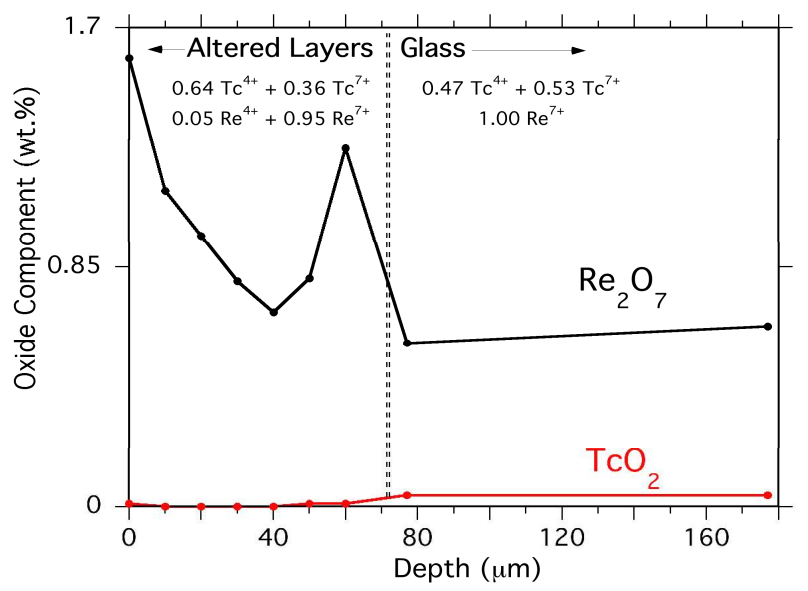

FIG. 3. Profiles of Tc and Re concentrations in 205 VHT coupon and XANES oxidation state results.

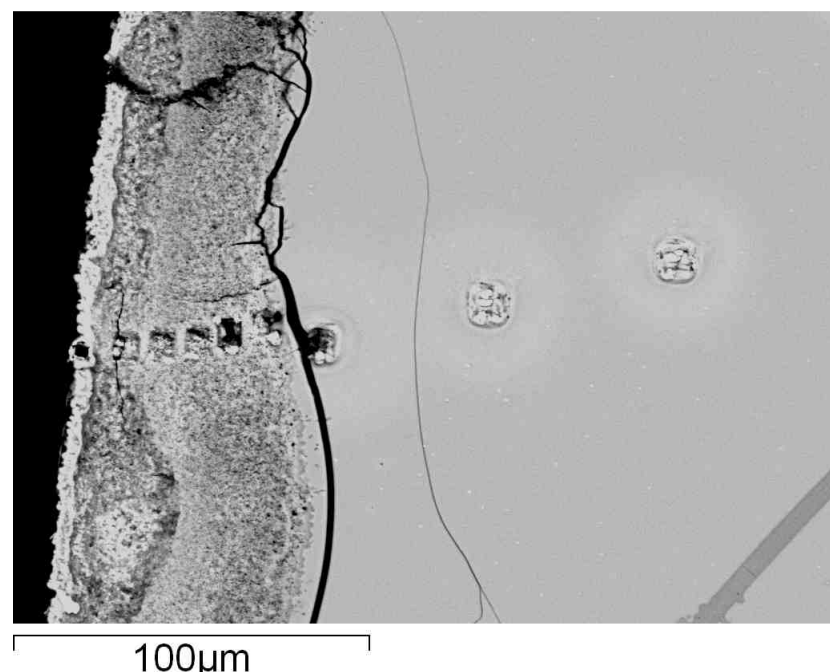

FIG. 2. Corroded layer on glass 219. Craters are WDS sampling points for composition profile.

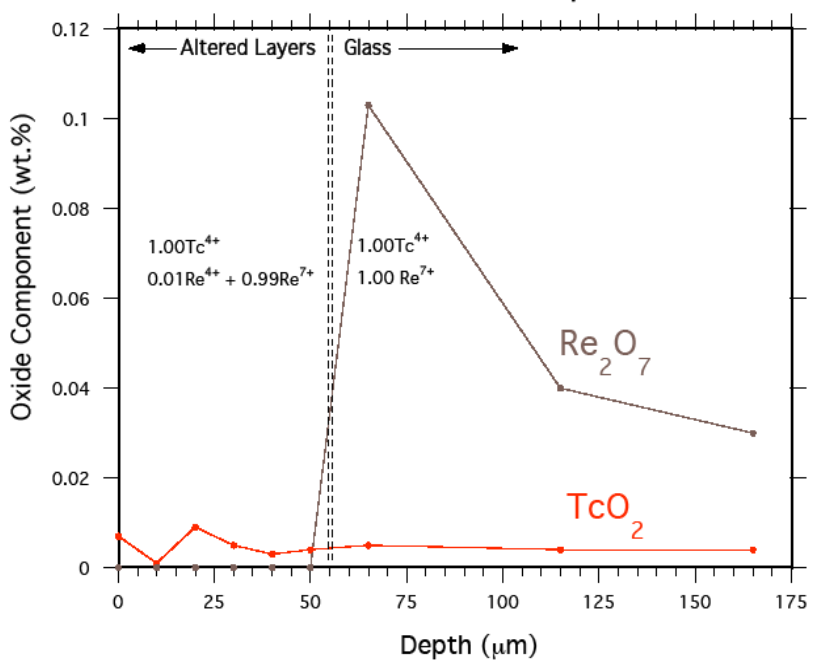

FIG. 4. Profiles of Tc and Re concentrations in 219 VHT coupon and XANES oxidation state results. 